\title{
Rhodnius amazonicus Almeida, Santos \& Sposina, 1973, Bona Species, Close to R. pictipes Stål, 1872 (Heteroptera, Reduviidae, Triatominae)
}

\author{
J-M Bérenger, D Pluot-Sigwalt ${ }^{+}$
} Laboratoire de Biologie et Evolution des Insectes, Ecole Pratique des Hautes Etudes et Muséum National d'Histoire Naturelle,
45 rue Buffon, F - 75005 Paris, France

The discovery of two atypical specimens of Rhodnius pictipes Stål, 1872 in French Guiana and the examination of the female holotype of R. amazonicus Almeida, Santos \& Sposina, 1973, the only specimen of this species so far known, lead us to propose the rehabilitation of $\mathrm{R}$. amazonicus synonymized with $\mathrm{R}$. pictipes. The male is described for the first time and the female redescribed. Both external characters and genitalia distinguish $\mathrm{R}$. amazonicus from $\mathrm{R}$. pictipes. R. amazonicus shows affinities not only with pictipes but also with R. stali Lent, Jurberg \& Galvão, 1993 and R. paraensis Sherlock, Guitton \& Miles, 1977. A key is provided for these four species forming, in all likelihood, a natural group, i.e. the "pictipes group".

Key words: Rhodnius amazonicus - bona species - redescription - French Guiana

Rhodnius amazonicus Almeida, Santos \& Sposina, 1973 was described as a species close to $R$. pictipes Stål, 1872 on the basis of a single female specimen. In their revision of the Triatominae, Lent and Wygodzinsky (1979) synonymized this species with $R$. pictipes on the basis of a photograph of the holotype of $R$. amazonicus. They argue that the specific characters are not convincing, or at least doubtful, and they consider this moreover partly damaged female as an abnormal specimen of $R$. pictipes.

The recent discovery of two atypical specimens among close to $100 R$. pictipes from French Guiana, allows us to reconsider this question. These two specimens, one male and one female, correspond exactly to the description made by Almeida et al. (1973); moreover, the male genitalia show clear differences from those of $R$. pictipes.

Further study of the two specimens from French Guiana and the examination of the female holotype lead us to propose the rehabilitation of $R$. amazonicus as a bona species. Within the genus, $R$. amazonicus shares morphological affinities, particularly in the genitalia, not only with $R$. pictipes, but also with $R$. stali Lent, Jurberg \& Galvão, 1993 and R. paraensis Sherlock, Guitton \& Miles, 1977, the four species constituting the "pictipes group".

\section{MATERIALS AND METHODS}

$R$. amazonicus may be very easily mistaken for $R$. pictipes; we have therefore carefully examined many specimens of $R$. pictipes belonging to the collections of the Muséum National d'Histoire Naturelle (MNHN, Paris) and the Institut Pasteur (Paris), to the personal collection of one of the authors (JMB) and to other private collections. Only two specimens of $R$. amazonicus have been found during this search.

The genitalia were examined in glycerol after $\mathrm{KOH}$ treatment. The photographs were realized with the photomicrographic system MC 100 (Zeiss).

\footnotetext{
${ }^{+}$Corresponding author. Fax: +33-1-40-79.3699. E-mail: dps@mnhn.fr

Received 30 January 2001

Accepted 10 September 2001
}

Rhodnius amazonicus Almeida, Santos \& Sposina, 1973, bona species (Fig. 1)

Material examined - Female holotype: (Est. Manaus Itacoatiara - km 180 - Manaus - AM. - 24.10.65 cols. Almeida \& Faustino Netto - isca luz) - (Rhodnius pictipes Stål, 1872, det. F.B. Almeida, 1970) - (lam. 1224) - (2751) (HEMIP 001) (Inpa, Instituto Nacional de Pesquisas da Amazônia, Manaus).

Nota: the posterior legs and one mesotibia are missing. The microscopic (slide) preparation being unavailable (Dr JA Rafael, pers. commun.), we have not been able to examine the genitalia.

Other specimens: French Guiana, 1 male: degrad Kwata sur crique Bagot, Cacao/ IX.1995, P.L., JM Bérenger leg., (MNHN collection); 1 female: Saül. VIII.1992, P Bleuzen leg. (JMB collection).

Description of the male (Fig. 1). Length: $16.5 \mathrm{~mm}$

Head: slightly granulose. Anteocular region brownish black with a yellowish brown median stripe. Antennae with first segment brown, second antennal segment $(=2.8 \mathrm{~mm})$ yellow on basal and brown on apical half; third and fourth segment missing. Postocular region wider than anteocular, yellowish, two black stripes from posterior margin of eyes to neck base. Head ventrally and rostrum, brown.

Thorax: anterior and lateral margins of the pronotum with yellowish carinae; collar angles rounded. Anterior lobe with 6 irregular black stripes; posterior lobe granulose, with six longitudinal dark stripes and $1+1$ submedian yellowish carinae. Pleura uniformly dark. Scutellum with a median blackish depression, bordered by two light brown stripes, apical process yellow at its apex. Corium uniformly dark, the veins yellow. Membrane brown, not reaching the posterior border of the abdomen. Femora dark, an inconspicuous yellowish ring in the median part of the metafemora (Fig. 2). Tibiae yellowish, a black ring in the middle.

Abdomen: broad, oval, venter dark. Connexivum yellow, a black triangular mark on each segment (Fig. 3).

Genitalia: posterior border of pygophore with a triangular median elevation in dorsal view (Figs 7, 9); internal margin with a sharp bispinose median process (Fig. 8). Paramere (Fig. 11) curved at right angles at the two thirds of its length. Phallus (Fig. 13): apex of the processus gonopori 


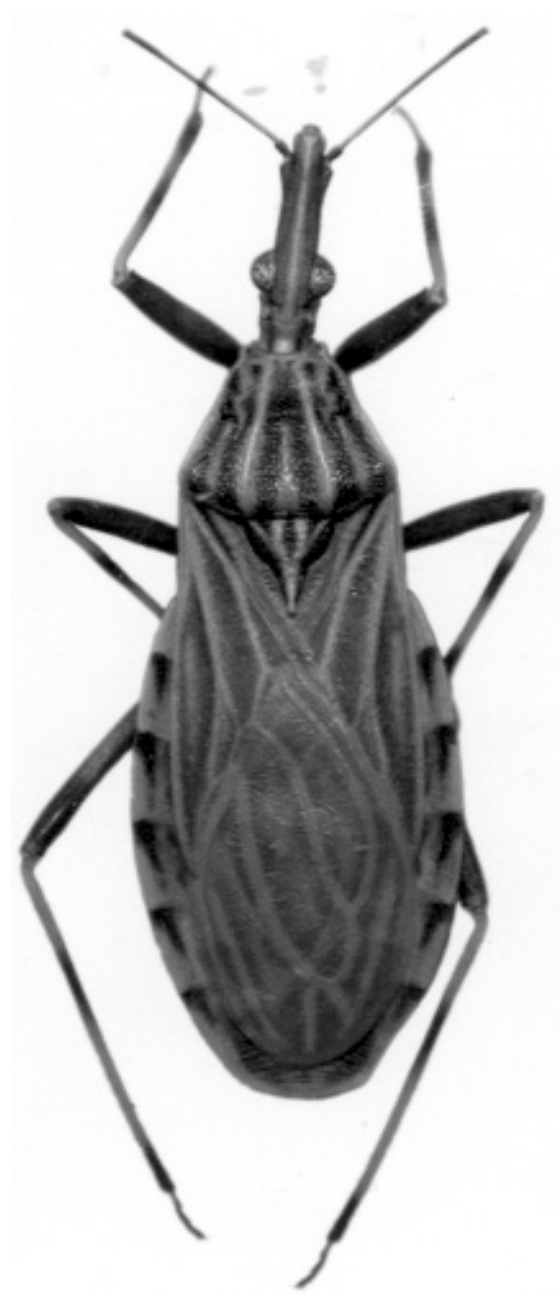

Fig. 1: Rhodnius amazonicus, habitus, male from French Guiana.

slender and elongated; phallosoma nearly oval, basal struts short, hooklike.

Redescription of the female. Lenght: $17 \mathrm{~mm}$

Habitus identical to the male. Antennal segments III and IV missing. Metafemora with median yellowish ring more conspicuous than in male. Lateral part of tergite IX projecting, tergite $\mathrm{X}$ hardly visible in dorsal and lateral view (Figs 6, 12).

Genitalia (Figs 21 to 23). Almeida et al. (1973) have given detailed drawings of the external genitalia of the holotype. These drawings correspond exactly to what we observed in the French Guiana female specimen and it seemed unnecessary to repeat them here. Instead, we present some photographs of the genital structures (Figs 21 to 23).

Biological data - The three known specimens of $R$. amazonicus have been caught at light trapping and nothing is known about their biology. As R. pictipes, it is a sylvatic species, but unlike pictipes, it seems rare.

Distribution - Brazil (Manaus), French Guiana (Cacao, Saül) Discussion - The two additional specimens of $R$. amazonicus kept their hind legs (missing in the holotype) and one of them is a male providing good genitalic characters. $R$. amazonicus is easily distinguishable from $R$. pictipes, apparently the most closely related species, by a set of characters (Table).

Relationships: the pictipes group - The rehabilitation of $R$. amazonicus and the recent description of two species,

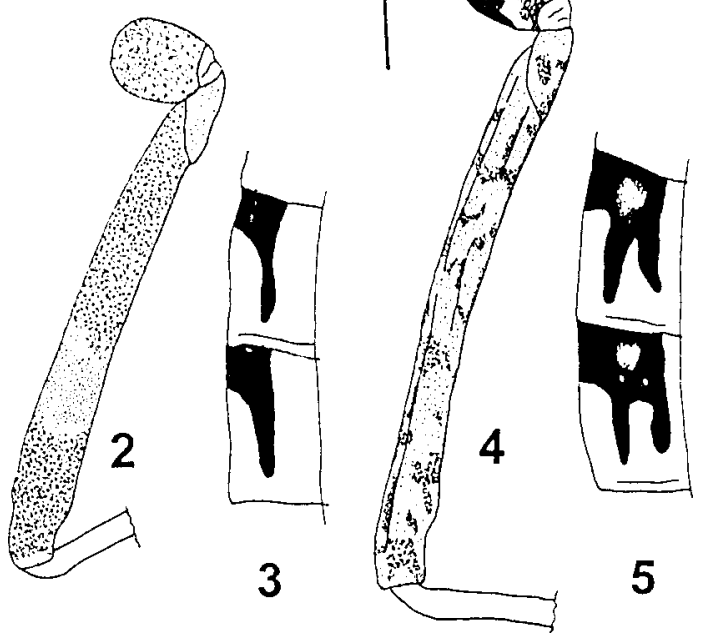

Fig. 2: Rhodnius amazonicus, posterior femora, coxae and trochanter. Fig. 3: id., dorsal connexival pattern (segments IV and V). Fig. 4: Rhodnius pictipes, posterior femora. Fig. 5: id., dorsal connexival pattern; $\mathrm{Bar}=1 \mathrm{~mm}$

R. stali and R. colombiensis Meija, Galvão \& Jurberg, 1999, add the number of species known to belong to the genus Rhodnius up to 15 ; there were only 12 species recognized in Lent and Wygodzinsky (1979).

If we take the whole genus into account, $R$. paraensis and $R$. stali can be considered as close to R. amazonicus and $R$. pictipes, on two shared characters in the four species: the bifid structure of the median posterior process of the pygophore and the presence of a median black ring on the tibiae.

As previously shown by Meija et al. (1999), the median process of the pygophore is not bispinose in the other species of the genus, more often acute ( $R$. brethesi, colombiensis, dalessandroi, ecuadoriensis, neivai, neglectus, nasutus, pallescens, prolixus, robustus), or subrectangular ( $R$. domesticus). We can add that all these species lack a median black ring on the tibiae. The "pictipes group" characterized here, comprises exactly the same species as the "group 2" established by Meija et al. (1999) mainly on the basis of phallic structures. Note however that other morphological data (Carcavallo et al. 1994) based on alternative, probably minor characters (oculo-ocellar region) do not confirm the affinities between the four species of this group.

$R$. pictipes, $R$. stali and $R$. amazonicus seem closely related by all main characters; $R$. paraensis differs by its small size (10.5 to $12 \mathrm{~mm}$ ), short head, antennae and legs, characters considered as plesiomorphic by Lent and Wygodzinsky (1979); R. stali also shows a preocular region short for the genus.

Key of the Rhodnius species belonging to the pictipes group

1 - At least the meso- and the metatibiae with a black median ring; median process of pygophore bispinose pictipes group

- Tibiae without black median annuli; median process of pygophore simple or rectangular ....

..(other species of Rhodnius) 
2 - Head short; protibiae without black median ring; length $<15 \mathrm{~mm}$ paraensis

- Head elongate; all tibiae with a black median ring; length $>15 \mathrm{~mm}$

3 - Anteocular region of the head 2,5 times as long as postocular stali

- Anteocular region of the head at least 2,7 times as long as postocular 4
4-Corium brownish, irregularly spotted with black; femora yellowish, mottled with dark brown. Median process of pygophore and paramere as shown respectively in Figs 16 and 19 pictipes

- Corium brownish, veins yellowish, without black spot; femora uniformly brownish, a yellowish median ring on metafemora; median process of pygophore and paramere as in Figs 8 and 11 amazonicus

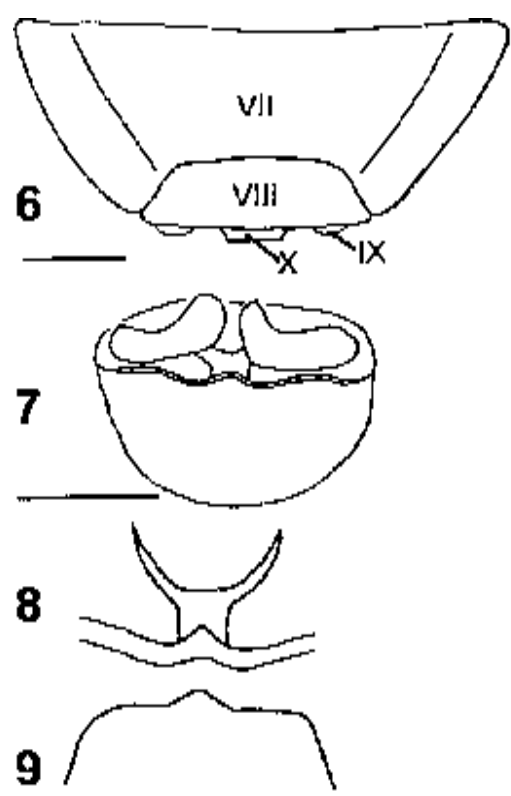

13
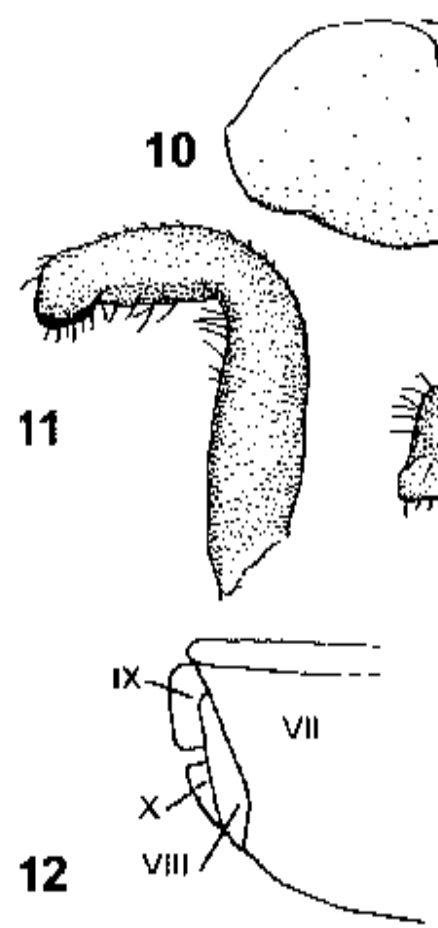

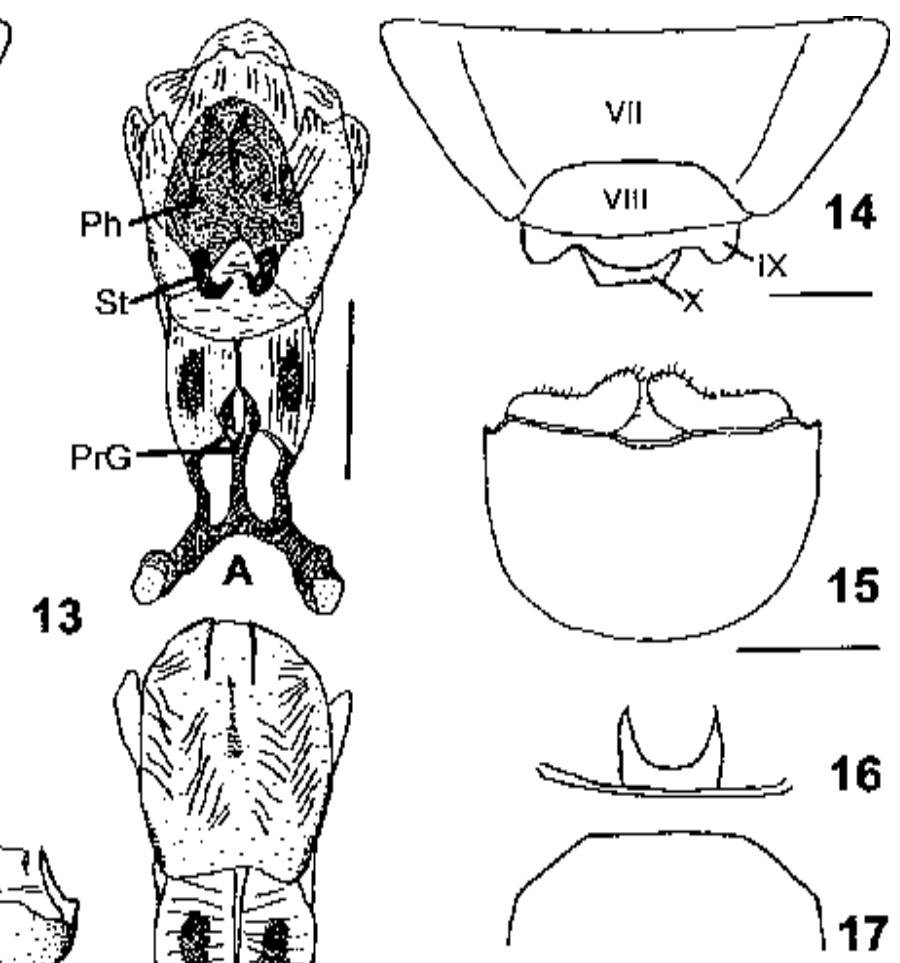

Morphological details, comparison between Rhodnius amazonicus (6 to 13) and R. pictipes (14 to 20) - Fig. 6: R. amazonicus, posterior border of the abdomen (female), dorsal view. Fig. 7: id., pygophore, posterior view. Fig. 8: id., median process of pygophore, caudal view. Fig. 9: id., posterior margin of pygophore, dorsal view. Fig. 10: id., pygophore (without parameres), lateral aspect. Fig. 11: id., right paramere, inner face. Fig. 12: female genitalia, lateral view. Fig. 13: id., phallus, ventral $(\mathrm{A})$ and dorsal $(\mathrm{B})$ views $[\mathrm{Ph}=$ phallosoma; St $=$ struts (processes of phallosoma); PrG = processus gonopori]; compare with figs 150 and 151 of $R$. pictipes in Lent and Jurberg (1969). Fig. 14: $R$. pictipes, posterior border of the abdomen (female), dorsal view. Fig. 15: id., pygophore, posterior view. Fig. 16: id., median process of pygophore, caudal view. Fig. 17: id., posterior margin of pygophore, dorsal view. Fig. 18: id., pygophore (without parameres), lateral aspect. Fig. 19: id., right paramere, inner face. Fig. 20: female genitalia, lateral view; Bar $=1 \mathrm{~mm}$ 

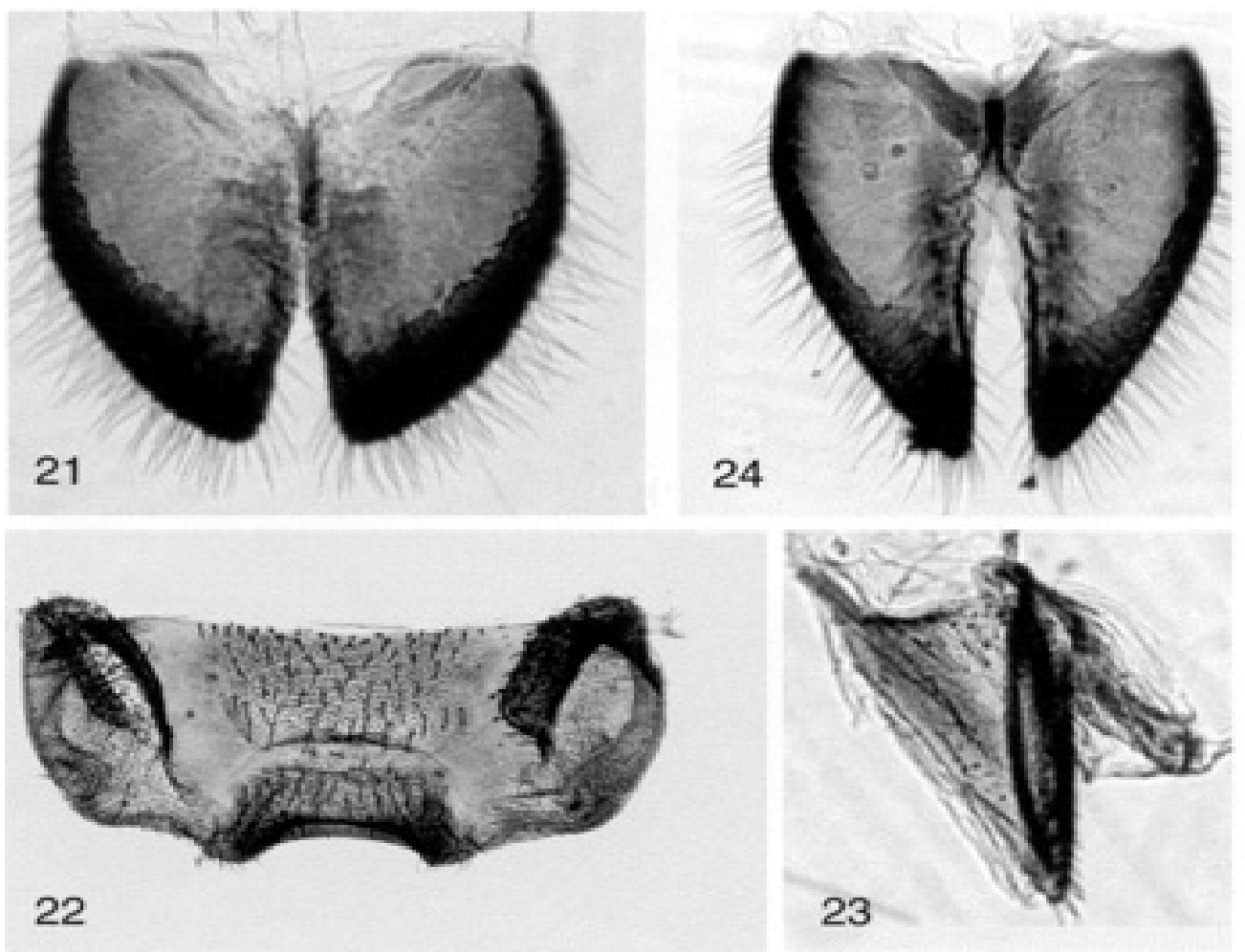

Female genitalia - Fig. 21: Rhodnius amazonicus, gonocoxite IX. Fig. 22: id., tergites IX and X. Fig. 23: id., gonapophyse IX. Fig. 24: Rhodnius pictipes, gonocoxite IX

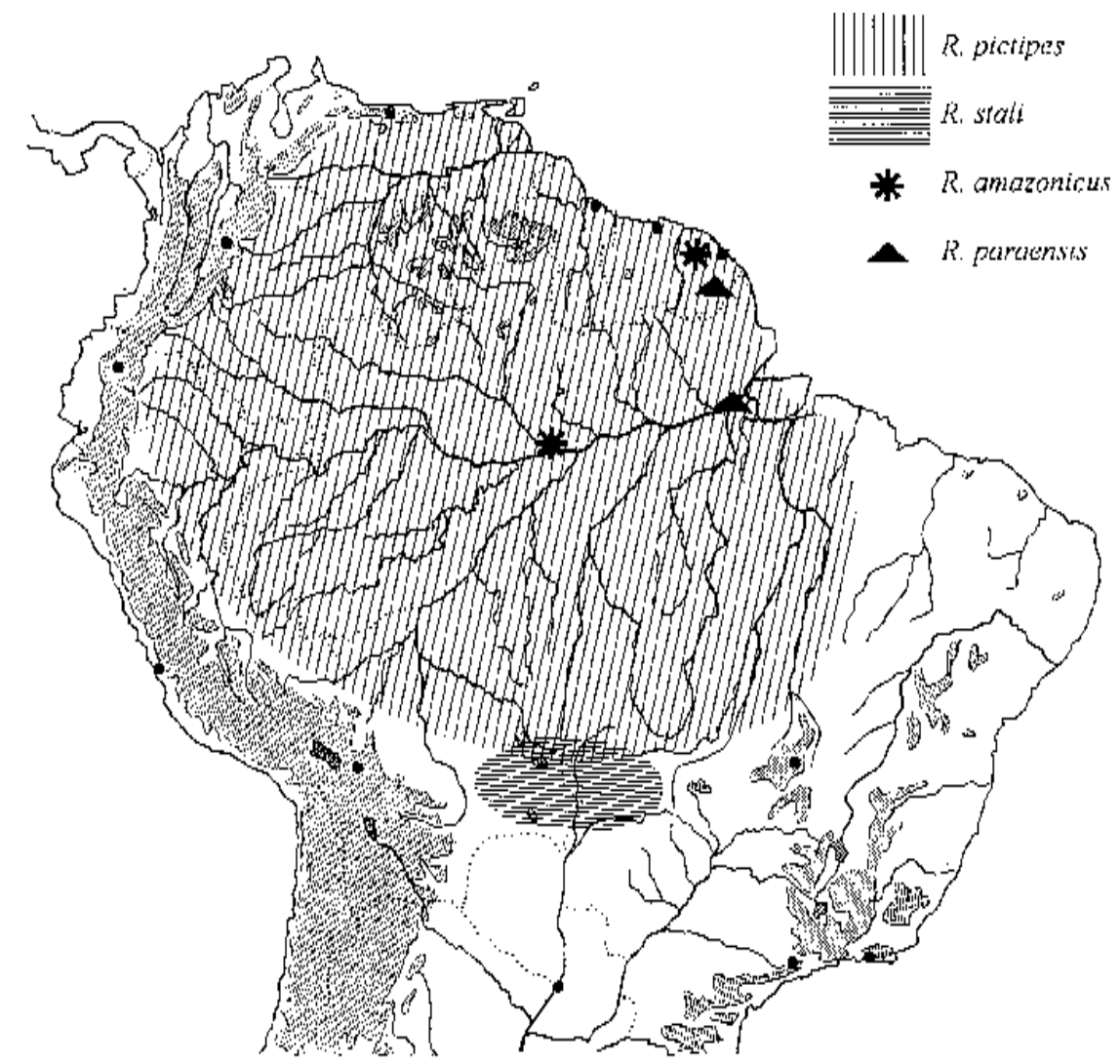

Fig. 25: geographical distribution and localities of the species belonging to the "pictipes group" [data from Lent \& Wygodzinsky (1979), Lent et al. (1993), Galíndez et al. (1996) and present paper] 
TABLE

Main distinguishing characters between Rhodnius amazonicus and R. pictipes

Rhodnius amazonicus Almeida et al.,1973

Pronotum granulose

Femora uniformly dark, a yellow ring on metafemora (Fig. 2)

Corium uniformly dark

Median process of pygophore with elongate and narrowed base (Fig. 8)

Phallosoma nearly oval (Fig. 13A)

Tergite X (female), slightly visible in dorsal view (Fig. 6)
Rhodnius pictipes Stål, 1872

Pronotum very granulose, rugose

Femora yellowish, dark brown spotted (Fig. 4)

Corium brownish with irregular blackish mottling

Median process of pygophore with short base (Fig. 16)

Phallosoma enlarged at base (see Lent et al., 1993)

Tergite X clearly visible in dorsal view (Fig. 14)

\section{DISTRIBUTION}

Fig. 25 shows the respective distribution of the four species belonging to the pictipes group. $R$. pictipes is the most widespread in South America (Belize, Bolivia, Brazil, Colombia, Ecuador, French Guiana, Guyana, Peru, Surinam, Trinidad, Venezuela) and occurs also in Central America (Lent \& Wygodzinsky 1979, Galíndez et al. 1996); it is sympatric, or at least parapatric (R. stali), with the three other species of the group. R. amazonicus and R. paraensis are localized in the Amazon Basin (Brazil, Pará; French Guiana). $R$. stali is restricted to the center of Brazil (Mato Grosso) and to Bolivia (Chiaparé) and is apparently allopatric with the two previous species.

Remark. $R$. paraensis previously known from Pará, was recently discovered in French Guiana through a single specimen captured by one of us (JMB) in Cacao; it is one of the 12 triatomines species recorded presently from French Guiana (Aznar et al. 2000).

\section{ACKNOWLEDGMENTS}

To our colleagues and friends for their help during this study, particularly for providing specimens from institutional collections or from their own collections. Namely: Dr Raphael (Laboratório de Parasitologia, Inpa, Manaus), Dr Magalenaes (Inpa, Manaus), Guy Couturier, Alex Delobel and G Tavakilian (IRD, antenne Muséum, Paris), Dr F Rodhain (Institut Pasteur, Paris), Dr Chantal Garabedian (Centre Hospitalier Général du pays d'Aix), Patrick Bleuzen (Paris), David and Laurence Rignon (French Guiana).

\section{REFERENCES}

Almeida F de B, Santos EI, Sposina G 1973. Triatomíneos da Amazônia III. Acta Amaz 3: 43-46.

Aznar C, Bérenger JM, Garrouste R, Hontebeyrie M, Carme B, Pluot-Sigwalt D 2000. Triatomines species (Hemiptera, Reduviidae, Triatominae) and Trypanosoma cruzi in French Guiana. International Congress of Entomology, Iguassu, Brazil 1926 August 2000, vol. II: 763.

Carcavallo RU, Jurberg J, Martínez A, Galíndez Giron I 1994. La region oculo-ocelar en el género Rhodnius Stal, 1859 (Hemiptera, Reduviidae, Triatominae). Entomol Vect 1: 21-32.

Galíndez I, Curto de Casas SI, Carcavallo RU, Jurberg J, Mena Segura CA 1996. Geographical distribution and alti-latitudinal dispersion of the tribe Rhodniini (Hemiptera, Reduviidae, Triatominae). Entomol Vect 3: 3-20.

Lent H, Jurberg J 1969. O genero "Rhodnius" Stal, 1859, com um estudo sôbre a genitalia das especies (Hemiptera, Reduviidae, Triatominae). Rev Brasil Biol 29: 487-560.

Lent H, Wygodzinsky P 1979. Revision of the Triatominae (Hemiptera, Reduviidae), and their significance as vectors of Chagas' disease. Bull Am Mus Nat Hist NY 163: 123-520.

Lent H, Jurberg J, Galvão C 1993. Rhodnius stali n. sp., afim de Rhodnius pictipes Stal, 1872 (Hemiptera, Reduviidae, Triatominae). Mem Inst Oswaldo Cruz 88: 605-614.

Mejia JM, Galvão C, Jurberg J 1999. Rhodnius colombiensis sp. n. da Colômbia, com quadros comparativos entre estruturas fálicas do gênero Rhodnius Stål, 1859 (Hemiptera, Reduviidae, Triatominae). Entomol Vect 6: 601-617.

Sherlock I A, Guitton N, Miles M 1977. Rhodnius paraensis espécie nova do Estado do Pará, Brasil. Acta Amaz 7: 7174. 
